\title{
Investigation of Sawmill Management and Technology on Waste Reduction at Selected Sawmills in Moratuwa
}

\author{
Caldera H.T.S. ${ }^{*}$ and Amarasekera H.S. \\ Department of Forestry and Environmental Science, Faculty of Applied Sciences, \\ University of Sri Jayewardenepura, Nugegoda, Sri Lanka \\ *savindi.c@gmail.com
}

\begin{abstract}
The demand for sawn timber and wood-based products is rising steadily with new developments in the country apart from the growing domestic consumption. Therefore it is imperative to strike a balance between the increasing demand and the optimum utilisation of the available forest resources.

Thus the key objective of this study was to investigate the effects of sawmilling management and technological parameters on loss in conversion from logs to sawn timber. A sample of twenty one sawmills was selected out of 206 registered private sawmills in Moratuwa according to the sampling percentages determined from an initial survey. Based on the results mean percentage loss in conversion of private sawmills in Moratuwa was 56.9\%. Significant differences were observed in loss in conversion values of both Teak and Mahogany species between the three categories of sawmills (frame sawmill, band sawmill and circular sawmill) as well as within the sawmills of the same category. Highest wastage was recorded in the circular saw which was $64.4 \%$. Percentage loss in conversion values were relatively low in frame saw and band saw which were $54.3 \%$ and $46.0 \%$ respectively. The results proved that the percentage loss in conversion varied between Teak and Mahogany species where Mahogany sawn in circular saw showed the highest percentage loss in conversion and Mahogany sawn using the horizontal band saw showed the lowest percentage loss in conversion. The study further revealed that the loss in conversion values of private band sawmills did not significantly vary with the State Timber Corporation band sawmills in Kaldemulla.
\end{abstract}

The reasons for variation in loss in conversion values can be attributed to sawyer's experience, the state of saw doctoring (saw sharpening and maintenance), cutting pattern, availability of log alignment equipments and saw guards and feed speed. It was observed that high wastage was caused by using thick tungsten carbide tipped blades used in circular sawmills. In contrast lowest loss in conversion was showed in band sawmills with thin flexible cutting blades. Through and through sawing method was found to be the only sawing method employed by all the selected sawmills. However it was identified that this method cannot be recommended for all logs especially for defective logs. As a mix of sizes is produced from a log in these sawmills cant sawing can be suggested as an efficient sawing method.

Keywords: Sawmill, Loss in conversion, Waste reduction 